\title{
Synthesis and Characterizations of a Collagen-Rich Biomembrane with Potential for Tissue-Guided Regeneration
}

\author{
Fábio D. Nascimento ${ }^{4}$ \\ ${ }^{1}$ Universidade Anhanguera de São Paulo-UNIAN, Osasco, SP, Brazil \\ 2Universidade de Araraquara, Núcleo de Pesquisa em Biotecnologia, \\ Centro, Araraquara, SP, Brazil \\ ${ }^{3}$ Biotechnology and Innovation in Health Program, Universidade \\ Anhanguera de São Paulo (UNIAN/SP), São Paulo, SP, Brazil \\ 4Universidade de Mogi das Cruzes, Centro de Ciências Biomédicas, \\ Mogi das Cruzes, SP, Brazil
}

Marcos J. Silva ${ }^{1,2,3}$ Carolina P. Gonçalves ${ }^{1} \quad$ Kleber M. Galvão ${ }^{1}$ Paulo H. P. D’Alpino ${ }^{3}$

Eur J Dent 2019;13:295-302

\begin{abstract}
Address for correspondence Paulo Henrique Perlatti D’Alpino, DDS, MSc, PhD, Biotechnology and Innovation in Health Program, Universidade Anhanguera de São Paulo-UNIAN SP Campus Pirituba,São Paulo,SP 05145-200, Brazil (e-mail: paulodalpino@gmail.com).
\end{abstract}

\begin{abstract}
Keywords

- extracellular matrix

- porcine intestinal submucosa

- guided bone regeneration

Objectives In this study, a collagen-rich biomembrane obtained from porcine intestinal submucosa for application in guided bone regeneration was developed and characterized. Then, its biological and mechanical properties were compared with that of commercial products (GenDerm [Baumer], Lumina-Coat [Critéria], Surgitime PTFE [Bionnovation], and Surgidry Dental F [Technodry]).

Materials and Methods The biomembrane was extracted from porcine intestinal submucosa. Scanning electron microscopy, spectroscopic dispersive energy, glycosaminoglycan quantification, and confocal microscopy by intrinsic fluorescence were used to evaluate the collagen structural patterns of the biomembrane. Mechanical tensile and deformation tests were also performed.

Statistical Analysis The results of the methods used for experimental membrane characterizations were compared with that obtained by the commercial membranes and statistically analyzed (significance of $5 \%$ ).

Results The collagen-rich biomembrane developed also exhibited a more organized, less porous collagen fibril network, with the presence of glycosaminoglycans. The experimental biomembrane exhibited mechanical properties, tensile strength, and deformation behavior with improved average stress/strain when compared with other commercial membranes tested. Benefits also include a structured, flexible, and bioresorbable characteristics scaffold.

Conclusions The experimental collagen-rich membrane developed presents physical-chemical, molecular, and mechanical characteristics similar to or better than that of the commercial products tested, possibly allowing it to actively participating in the process of bone neoformation.
\end{abstract}

\section{Introduction}

Tissue engineering is based on the study of the manipulation and development of the interactions of molecules, cells, tissues, or organs aiming at the restoration or improvement of impaired tissue function. ${ }^{1}$ It is a science of multidisciplinary scope, in which researchers from different areas interact to exchange knowledge and experiences to provide 
solutions to the various challenges of regenerative medicine. There is no consensus on the choice of the ideal material to be used for tissue and bone regeneration, considering that it is usually a matter of personal, professional preference. Numerous scaffolds produced from a variety of biomaterials and manufactured using a variety of fabrication techniques have been used. ${ }^{2}$ Concerns have been expressed over important characteristics when designing or determining the suitability of a scaffold for use in tissue engineering, such as biocompatibility, biodegradability, mechanical properties, scaffold architecture, and manufacturing technology. ${ }^{3}$ These characteristics are determining factors when choosing a biomaterial in a successful tissue engineering approach. ${ }^{4}$ The evolving technology of tissue engineering for dental tissues in a short time will certainly allow a significant change in terms of the availability of innovative products on daily basis use for the clinicians. ${ }^{5}$ In this way, when implanted at the side of an injury, a scaffold material should aim at repopulation by endogenous cells and remodeling by the recipient as well. ${ }^{6}$

Synthetic or natural materials presenting proved cellular interaction, bioabsorption, biocompatibility, and improved mechanical properties have been used in dentistry. Previous studies have demonstrated that these materials can carry cells, promoting initial support, facilitating tissue nutrition and metabolism. ${ }^{7-10}$ One of the main problems related to the application of biomembranes is the mechanical strength necessary to withstand the cyclic forces, being active in participating in the regeneration process of the area in which it was implanted, and being able to function as a niche for cell growth and differentiation. ${ }^{11}$ In this context, the synthesis of a biomaterial should mimic the structure of the extracellular matrix not only in terms of its molecular characteristics but also in terms of its mechanical properties, allowing its application and stability during and after surgical procedures. ${ }^{12}$ Thus, biodegradable materials used for bone repair and regeneration applications require better control of interfacing between the material and the surrounding bone tissue and also improved mechanical properties and degradation/ resorption profiles to expand their indications and achieve improved clinical outcomes. ${ }^{13}$

The extracellular membrane scaffold derived from porcine small intestinal submucosa is the biological scaffold material that has been extensively characterized, used as a prototypical extracellular membrane scaffold. The scaffold derived from porcine small intestinal submucosa is composed of at least 90\% collagen. The great majority of the collagen is type I, with minor amounts of collagen types III, IV, $\mathrm{V}$, and VI also present. ${ }^{14}$ Scaffolds derived from porcine small intestinal submucosa contain a variety of glycosaminoglycans, including heparin, heparin sulfate, chondroitin sulfate, and hyaluronic acid. ${ }^{15}$ The number of glycosaminoglycans remaining in tissue after decellularization depends significantly on the method of decellularization. For example, ionic detergents are often used in the decellularization process, and such detergents can remove glycosaminoglycans from the extracellular membrane. ${ }^{16}$ Scaffold derived from porcine small intestinal submucosa has been shown to contain adhesion molecules such as fibronectin and laminin,, 15,17,18 the proteoglycan decorin, and the glycoproteins biglycan and entactin. ${ }^{19}$ Various growth factors are also present in scaffolds derived from porcine small intestinal submucosa, including transforming growth factor- $\beta,{ }^{20,21}$ primary fibroblast growth factor- $\beta,{ }^{21,22}$ and vascular endothelial growth factor. ${ }^{23}$ Several of these growth factors have been shown to retain their bioactivity even after terminal sterilization and long-term storage. ${ }^{20,22}$

The purpose of the present study is to describe the synthesis and different characterizations of a collagen-rich biomembrane derived from porcine small intestinal submucosa, with the potential for tissue-guided regeneration in dentistry. The results obtained with this experimental biomembrane in terms of physicochemical and biological characteristics were compared with those of commercial membranes.

\section{Materials and Methods}

\section{Preparation of the Extracellular Matrix}

The process of obtaining the biomembranes produced in this study is described in patent document No. PI0805153-4 A2, available for consultation at the Brazilian National Institute of Industrial Property. The refrigerated material was cleaned and sliced in small pieces $\left(15 \mathrm{~cm}^{2}\right)$. The pieces were then washed thoroughly with ultrapure water, obtained by reverse osmosis and then washed in sodium hypochlorite solution $(0.1 \%)$ for 30 minutes under gentle agitation. Then, the specimens were water-rinsed and mechanically cleaned to remove residues. Next, the specimens underwent a thermochemical treatment by immersing them in an enzymatic solution based on sodium lauryl sulfate proteases for 12 hours under stirring. Then, the specimens were water rinsed with ultrapure water and subjected to another 12 hours treatment with an enzymatic solution, in which the base solution was a combination of sodium lauryl sulfate and lipase. Then, another water rinse with water for injection (WFI) was performed. The membranes were then stretched on a regular Teflon surface and then cooled to $3.5^{\circ} \mathrm{C}$ for 12 hours. The specimens were then placed in an oven at $40^{\circ} \mathrm{C}$ for 12 hours and at $65^{\circ} \mathrm{C}$ for another 12 hours with forced ventilation. Finally, the material was subjected to a chemical treatment in which the specimens were immersed in a solution of $1 \mathrm{M} \mathrm{HCl}$, under agitation for 24 hours. At the end of the incubation, the specimens were again washed in WFI ultrapure water and then lyophilized (Liotop L101, Liobrás, Brazil). In the present study, the experimental collagen-rich biomembrane was evaluated and its properties compared with that of four commercial biomembranes were widely used, which were obtained using different synthesis processes. - Table 1 shows the characteristics of all of the membranes included in the present study.

\section{Scanning Electron Microscopy and Energy Dispersive Spectroscopy Test}

For scanning electron microscopy (SEM) analysis, the membranes were cut into fragments $\sim 9 \mathrm{~mm}$ wide and fixed in aluminum support with the aid of an adhesive tape. The membranes were then subjected to the vacuum metallization process 
Table 1 Membranes evaluated in the present study

\begin{tabular}{|l|l|l|l|l|}
\hline Product & Manufacturer & Composition & Tissue type & Bioresorbable \\
\hline GenDerm & Baumer & bovine cortical bone membrane & Bovine bone & Yes \\
\hline Surgitime PTFE & Bionnovation & Type I collagen membrane & $\begin{array}{l}\text { Demineralized } \\
\text { bovine bone }\end{array}$ & Yes \\
\hline Surgidry Dental F & Technodry & $\begin{array}{l}\text { Organic matrix of Type I } \\
\text { collagen }\end{array}$ & $\begin{array}{l}\text { Sunthetic origin } \\
\text { erized bovine tissue }\end{array}$ & No \\
\hline $\begin{array}{l}\text { Experimental } \\
\text { Membrane }\end{array}$ & $\begin{array}{l}\text { Type I collagen; } \\
\text { glycosaminoglycan }\end{array}$ & $\begin{array}{l}\text { Porcine intestinal } \\
\text { submucosa }\end{array}$ & Yes \\
\hline
\end{tabular}

(Denton Vacuum Desk V, Denton Vacuum, Moorestown, New Jersey, United States) and gold sputtering. Then, the specimens were evaluated by SEM (Zeiss, model EVO LS15). Digital images were obtained through the detection of secondary signals of electrons emitted by the samples when exposed to the electron beams. To evaluate the atomic composition of the membranes, an X-ray energy dispersive spectroscopy (EDS) spectrometer (Oxford, model X-act) integrated to the SEM was used, where the chemical analysis was performed by dispersive energy of X-rays for all the elements of the periodic table (except for $\mathrm{H}, \mathrm{He}, \mathrm{Li}$, and $\mathrm{Be}$ ). A qualitative elemental analysis was performed to determine the chemical elements within the membranes tested, and the results were expressed in histograms.

\section{Extraction of Glycosaminoglycans and Agarose Gel Electrophoresis}

All of the membranes selected for this study received a perforation at room temperature and were then placed in a $100 \%$ acetone solution to remove the lipids. The fragments were then removed from the acetone and then dried in an oven at $50^{\circ} \mathrm{C}$ to obtain the ketone powder and the mass evaluated in an analytical balance. The dried powder was subjected to proteolysis by maxatase $4 \mathrm{mg} / \mathrm{mL}$ in $0.05 \mathrm{M}$ Tris- $\mathrm{HCl} \mathrm{pH} 8.0$ buffer with $1 \mathrm{M} \mathrm{NaCl}$ in the proportion of $1 \mathrm{~g}$ of ketone powder for every $20 \mathrm{~mL}$ of buffer under agitation. This solution was kept under constant stirring for 12 hours at $60^{\circ} \mathrm{C}$. After that, $90 \%$ trichloroacetic acid was added to the solution until reaching the final $10 \%$ concentration for the precipitation of nucleic acids and peptides. The solution was left still, without stirring for 20 minutes at $4^{\circ} \mathrm{C}$. After that, the material was centrifuged at 5,000 rpm for 20 minutes at room temperature, and the supernatant part discarded. Then, two volumes of methanol were added for the precipitation of glycosaminoglycans, which was performed at $-20^{\circ} \mathrm{C}$ (freezer) for 24 hours.

Further centrifugation was performed at 5,000 rpm for a further 20 minutes at room temperature and the supernatant discarded again. The precipitated material containing the glycosaminoglycans (GAGs) was oven dried and resuspended in distilled water in the proportion of $5 \mathrm{mg}$ ketonic powder to $10 \mu \mathrm{L}$ of distilled water. The compounds from the extraction were identified by agarose gel electrophoresis and quantified by densitometry. ${ }^{24,25}$ The identification of sulphated glycosaminoglycans was performed by comparing the electrophoresis migration of the samples with those of known and purified standards. These same standards were used for the quantitative determination of the compounds by means of densitometry at $525 \mathrm{~nm}$. For this purpose, the Quick Scan 2000 Win densitometer (Helena Laboratories Beaumont, Texas, United States) was used. The patterns used were chondrocyte sulfate, extracted from whale cartilage; dermatan sulfate, extracted from porcine intestinal mucosa and porcine lung heparan sulfate.

\section{Evaluation of the Collagen Structural Pattern by Second Harmonic Generation Confocal Microscopy}

Fragments of $10 \mathrm{~mm}^{2}$ were taken without any type of treatment to the confocal scanning and laser microscope (Germany), previously configured with the following excitation pattern: Titanium-Sapphire Laser (Ti-S) in pulses that ranged from 100 to 200 fs at a wavelength of 1,600 nm and multiphoton incidence. The images were generated in Z-axis variant planes in sections of $12 \mu \mathrm{m}$ until the threedimensional (3D) image could be formed and the collagen visualization pattern was evaluated.

\section{Evaluation of Mechanical Properties of Membranes}

The analyses of all the samples were performed in triplicate using a Filizola traction equipment, model BME-20kN, with a load cell of $50 \mathrm{~N}$ ( $5 \mathrm{kgf}$ ), resolution of $0.003 \mathrm{~N}$, and the claws' separation speed at $20 \mathrm{~mm} / \mathrm{min}$.

\section{Statistical Analysis}

For the analysis of possible differences among the groups, the analysis of variance test was used followed by the Tukey-Kramer multiple comparisons test (parametric data) and Student's t-test (significance 5\%).

\section{Results and Discussion}

\section{Scanning Electron Microscopy and Energy Dispersive Spectroscopy}

-Fig. 1 illustrates the SEM analysis of the surface of various membranes from different manufacturers. In the morphology of the GenDerm brand membrane (-Fig. 1 [1A and 2B]), it is possible to notice the typical characteristics of partially mineralized tissue and a coherent histological organization of porcine origin. Presence of large diameter pores, possibly remnants of Haversian canals, and even remnants of structures that appear to be osteocytes, which even after 


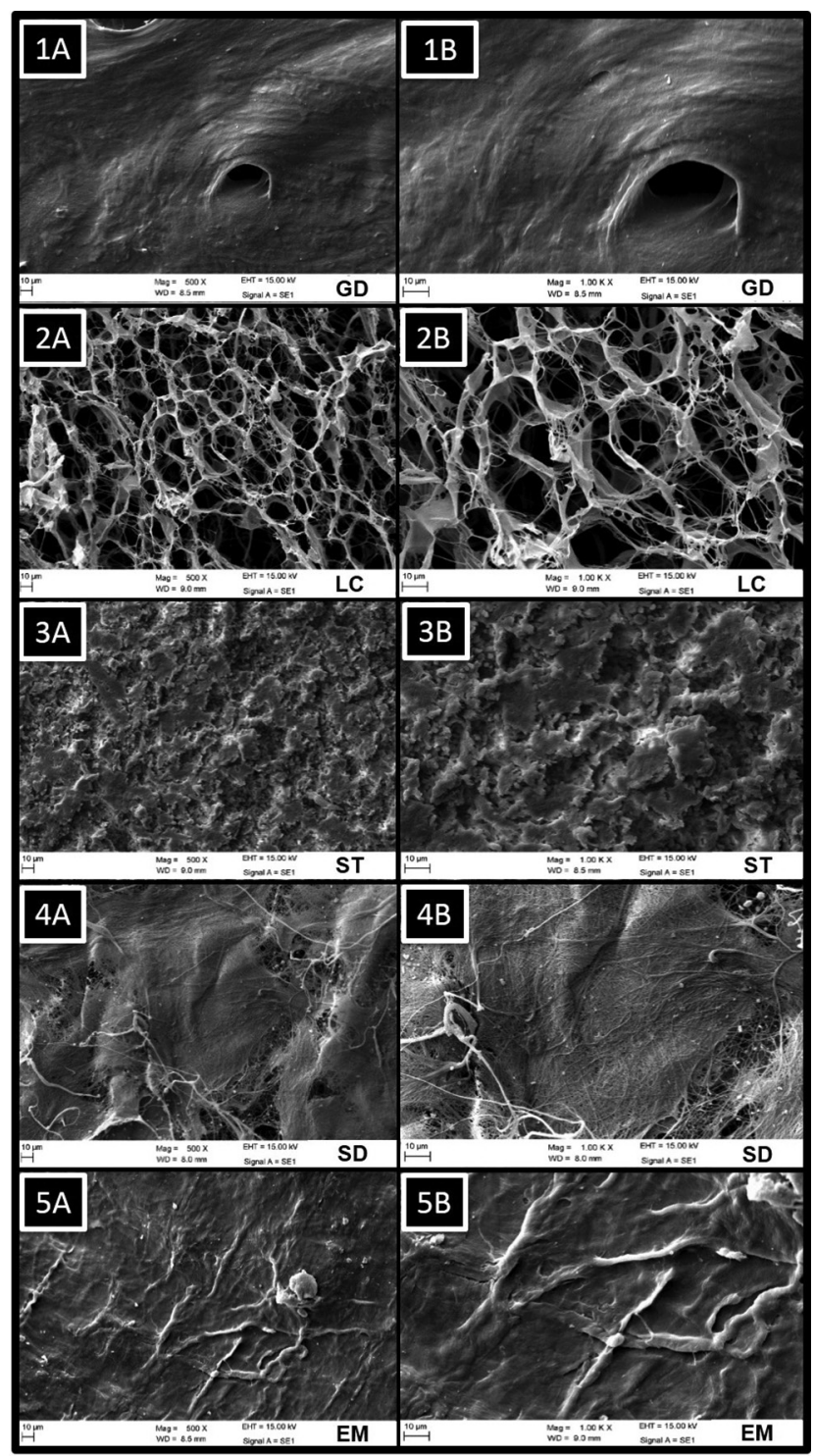

Fig. 1 Evaluation by scanning electron microscopy of biological membranes of several manufacturers: (1A and 1B) GenDerm (1,000x and 3,000x zoom, respectively); (2A and $2 \mathrm{~B})$ Lumina-Coat $(1,000 \times$ and $3,000 \times$, zoom, respectively); $3 A$ and $3 B(1,000 \times$ and $3,000 \times$, zoom, respectively); $5 \mathrm{~A}$ and $5 \mathrm{~B}$, Experimental Membrane $(1,000 \times$ and 3,000×, zoom, respectively).

treatment, are still adhered to the membrane. The morphology of the surfaces varied considerably among the studied membranes. Lumina-Coat membrane ( - Fig. $1[2 \mathrm{~A}$ and $\mathrm{B}]$ ) exhibited a heterogeneous distribution of collagen fibers, resulting in a surface with high porosity, and also a high variation in terms of pore diameter. - Fig. 1 (3A and B) displays images of synthetic membrane Surgitime PTFE, which is a polytetrafluoroethylene-rich, polymer-based membrane. This membrane exhibited overlapping layers of polymers, resembling scales. Distinctly less porous, Surgitime PTFE membrane seems to be less permeable when compared with other membranes evaluated in this study. On the surface of the Surgidry Dental F membrane ( - Fig. 1 [4A and B]), a different pattern from that of previously presented in the distribution of the collagen fibers was noticed. In this membrane, the fibers were found to be less thick and are distributed in a more disorganized way. On the other hand, due to these characteristics, the molecular frame is more cohesive and consequently less porous.

- Fig. 1 also exhibits the morphological characteristics of the Experimental Membrane ( $\boldsymbol{- F i g . ~ 1 , 5 A}$ and B), which exhibited thicker and larger collagen fibers, clearly superior to that of other membranes evaluated. Comparatively, the Experimental Membrane was found to be less porous in comparison with other membranes of animal origin. A characteristic less porous membrane seems to be clinically accepted by the clinicians considering the need to avoid an excessive humidity and subsequent loss of the membrane physical properties. The biological concepts of guided tissue and bone regeneration are based on the establishment of a protective barrier for the blood clot and resident cells by means of the interposition of a physical barrier between the gingival flap and the bone defect, or migration of the epithelium over the dental root. ${ }^{26}$ When in contact with membranes, undifferentiated mesenchymal cells are expected to repopulate the repair sites giving rise to the periodontal ligament and to the bone tissue. ${ }^{27}$ Several studies support the knowledge that collagen promotes adhesion of several cell types, allowing them to remain in vitro for long periods, and stimulating cell proliferation..$^{28}$ The structure and composition of the membrane determine the time of degradation, its spatial conformation, and the tissue reactions. If the membrane tends to collapse in the bone defect, this limits the space for bone regeneration. ${ }^{29}$ In its initial phase, a membrane's resistance is determined mainly by the rigidity of the material. From a practical point of view, it should also be able to adapt to the adjacent bone contours. ${ }^{28}$ The results showed considerable differences in the membrane architecture and their chemical composition when evaluated by the SEM. The Lumina-Coat membrane has an incredibly porous surface and also a wide variety of pore diameters; this may explain the low mechanical strength noted in the tensile test. A fact that also has to be considered is that this type of structural conformation also becomes more susceptible to degradation, reducing the time of bioabsorption, and with that diminishing its potential use as a physical barrier. The Surgidry Dental $F$ membrane has a surface formed by numerous frames arranged in a disordered manner, with large gaps intermingling the entire structure. This fragility was also detected in the failed test of the material even when subjected to low loads. It is also worth noting that the fragility of the structure entails loss of function as a barrier. GenDerm membrane surface has a more organized structure, but it has large cracks throughout its length. Although it has reached a great resistance in the traction test, with a response similar to a ceramic material, the cracks identified in the material could compromise its function as a protective barrier. Surgitime PTFE membrane has a surface arranged in nonhomogeneous layers interspersed with pores of different diameters. According to the tensile tests, this membrane demonstrated good mechanical resistance. However, this type of material requires a second surgical intervention for its removal, considering that it is a bioresorbable membrane. The Experimental Membrane has a surface composed of fibers that are homogeneous and arranged in parallel, similar to that of the collagen fibers 
in the extracellular matrix. This structure is quite organized, which demonstrated excellent performance in the tensile test, and the pores found on its surface are dispersed uniformly. ${ }^{30}$

The EDS evaluation allowed the identification of part of the chemical composition of each one of the membranes tested. The results show little significant differences in the chemical composition of the membranes, with emphasis only on the high concentration of fluoride, in the form of fluoride ion (F-), on the Surgitime PTFE membrane. Data are expressed as the percentage by weight, not considering the carbon and nitrogen atoms, which, due to the low atomic number, are not accurately quantified. - Table 2 presents the averages of the results obtained in the analyses of all of the membranes studied.

The results of the chemical analysis by ESD showed the presence of chemical elements and proportions of these different elements among the membranes analyzed. Elements such as magnesium $\left(\mathrm{Mg}^{2+}\right)$, fluorine $\left(\mathrm{F}^{-}\right)$, potassium $\left(\mathrm{K}^{+}\right)$, and chloride $\left(\mathrm{Cl}^{-}\right)$were detected ( - Table 2 ). These findings should be interpreted with caution as the results are expressed in percentages of the chemical element in relation to the total sample weight, and it does not consider carbon and nitrogen ions, the main components of the collagen molecules. The actual percentage of the other elements may be much lower. Even so, the presence of elements in varying proportions, such as chlorine and potassium, is an interesting finding and may constitute a contaminant derived from the processes of membrane fabrication.

\section{Quantification of Glycosaminoglycans}

-Fig. 2 illustrates the results concerning the presence of sulfated glycosaminoglycans in the composition of the membranes evaluated. It is noticeable that the Experimental Membrane was the only membrane to present $0.4 \mathrm{mg} /$ mg of dermatan sulfate sample, while the other membranes, perhaps due to the structural difference found in their extracellular membranes, presented no detectable levels of glycosaminoglycans in the composition.

\section{Structural Evaluation of Collagen Using Confocal Microscopy by Intrinsic Fluorescence}

As described previously in methods, the collagen molecule, when structured (in its native form), is capable of emitting fluorescence. - Fig. 3 shows in 3D how collagen is distributed on membranes. It should be highlighted that the Surgitime PTFE membrane, which is the only one of synthetic origin and therefore has no collagen fibrils in its structure. In this way, only the collagen membranes were evaluated. Supporting the data obtained by SEM, GenDerm membrane obtained

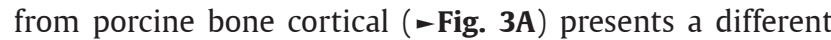
pattern of collagen distribution, clearly exhibiting regions with larger pores are located in the same areas in which the collagen fibrils are absent. The collagen filaments of Lumina-Coat membrane (-Fig. 3B) presented larger diameters also presenting regions with larger pores. - Fig. $\mathbf{3 C}$ shows the structural collagen pattern of the Experimental Membrane, which presented a profile of dense distribution of collagen, with fewer detectable pores. - Fig. 3D demonstrated that the Surgidry Dental $F$ membrane has thinner collagen filaments when compared with other membranes. In this way, this membrane presents a more regular surface, exhibiting lower fluorescence peaks when three-dimensionally analyzed using confocal microscopy. Also, it is possible to observe that the pore regions are equivalent to those observed in the Experimental Membrane.

\section{Mechanical Properties of the Membranes}

Some basic characteristics are necessary so that a membrane can be used in guided bone regeneration, which may include biocompatibility, cellular occlusion capacity, adaptation to surgical space (malleability), ease of handling by the surgeon, and mechanical resistance. ${ }^{31}$ The tensile strength test is the quickest and simplest way to evaluate the mechanical properties of the materials, being performed by traction of a test piece until its rupture. ${ }^{32}$ The tensile force is produced in the material when two forces in opposite directions are applied

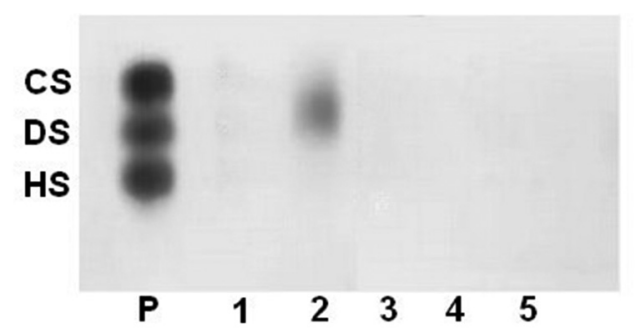

Fig. 2 Electrophoretic profile on 1.3-diaminopropane-acetate buffer (PDA) gel of sulfated glycosaminoglycans extracted from membranes: (P) standard, (1) Surgidry Dental F, (2) Experimental Membrane, (3) DermGen, (4) Lumina-Coat, and (5) Surgitime PTFE; (HS) heparan sulfate, (DS) dermatan sulfate, and (CS) chondroitin sulfate. EDS analysis of the membranes (A) Experimental Membrane, (B) Lumina-Coat, (C) GenDerm, (D) Surgitime PTFE, and (E) Surgidry Dental F. EDS, spectroscopic dispersive energy.

Table 2 EDS analyses of the membranes

\begin{tabular}{|l|c|c|c|c|c|c|c|c|c|}
\hline & $\mathrm{C}^{2+}$ & $\mathrm{N}^{3+}$ & $\mathrm{O}^{2-}$ & $\mathrm{K}^{+}$ & $\mathrm{Cl}^{-}$ & $\mathrm{Mg}^{2+}$ & $\mathrm{Na}^{+}$ & $\mathrm{F}^{-}$ & $\mathrm{Ca}^{+}$ \\
\hline GenDerm & 50.8 & 23.6 & 25.6 & & & & & & \\
\hline Lumina-Coat & 44.8 & 25.4 & 27.5 & & 2.4 & & & & \\
\hline Surgitime PTFE & 26.9 & & & & & & & 73.1 & \\
\hline Surgidry Dental F & 47.6 & 23.7 & 24.7 & & 2.3 & & 0.9 & & 1.0 \\
\hline Experimental Membrane & 48.0 & 21.1 & 27.5 & 0.6 & 0.3 & 0.7 & & & \\
\hline
\end{tabular}

Abbreviation: EDS, spectroscopic dispersive energy.

Values obtained from the average result, of the three-point analysis of each sample, and expressed as a percentage of the total weight, excluding carbon and nitrogen atoms. 

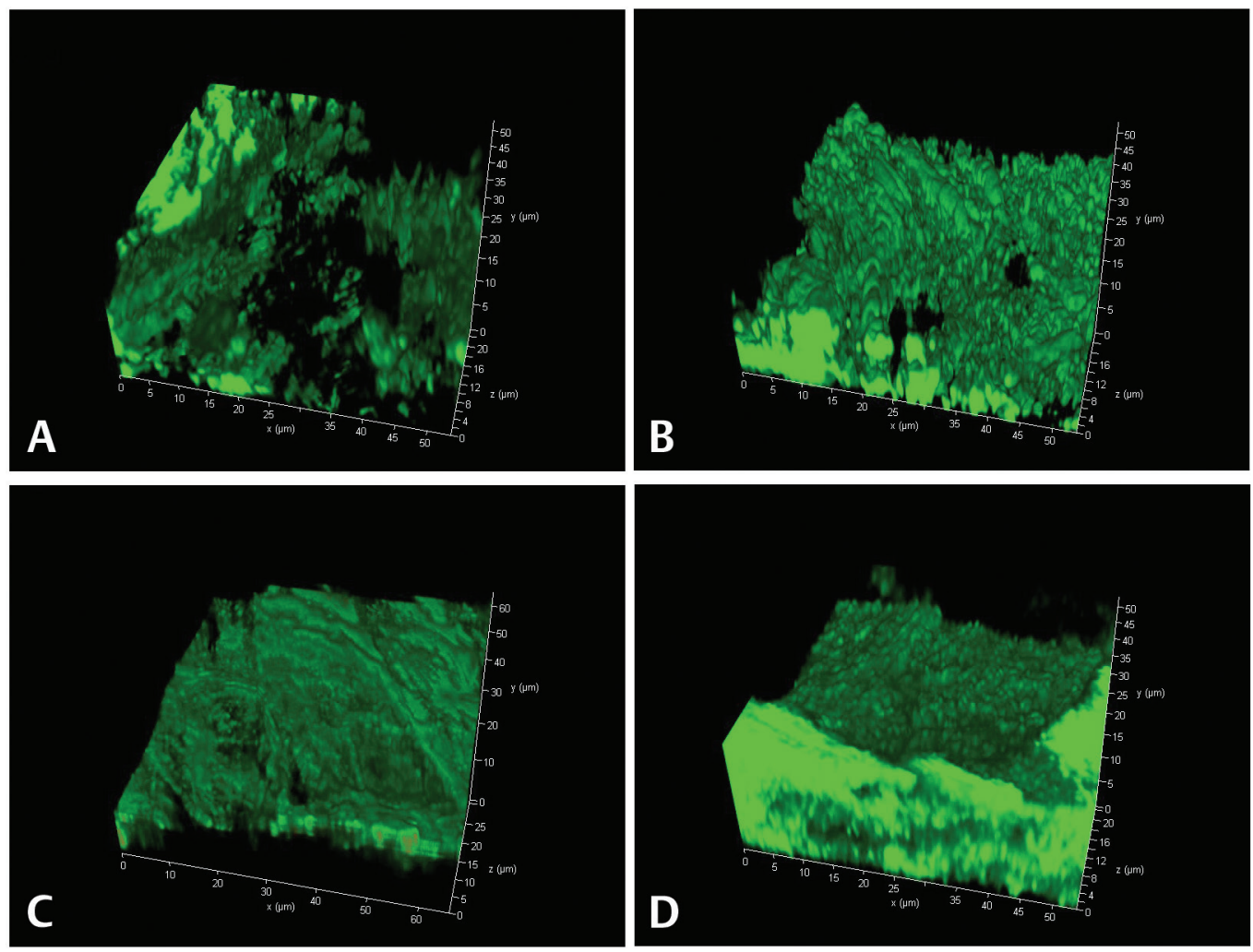

Fig. 3 Intrinsic collagen fluorescence observed by laser confocal microscopy: Membrane fragments, without any type of treatment, were observed by the structural profile of the collagen by autofluorescence. (A) GenDerm, (B) Lumina-Coat, (C) Experimental Membrane, and (D) Surgidry Dental F.

in the same line of application to elongate the material, and the tensile strength comes from the attractive molecular forces that tend to hinder the separation of the material..$^{33}$ In the present study, the maximum tensile strength of the membranes until their rupture was evaluated; that is, it clinically represents the membranes' ability to absorb the physiological and external loads imposed at the implant site. This information is essential, considering that clinically speaking the implant site may be subject to a wide variety of experimented loads. ${ }^{34}$-Figs. $\mathbf{4}$ and $\mathbf{5}$ display the results of tensile strength and percentage of deformation of the membranes studied in this study.

GenDerm membrane presented a mechanical resistance significantly superior to that of others, with a tension value of $19 \mathrm{MPa}$, against less than $3 \mathrm{MPa}$ of the other materials, but it was the most brittle, which according to the manufacturer it needs at least 5 minutes to moisturize and become more flexible and safer for handling. The GenDerm sample obtained an average deformation of $10 \mathrm{MPa}$, the others above $20 \mathrm{MPa}$, except the Surgidry Dental F material that presented a deformation of $18 \mathrm{MPa}$. Surgitime PTFE membrane presented a deformation of $36.7 \%$, and had the third best mechanical property, with $3 \mathrm{MPa}$ of tension. The Experimental Membrane developed in the present study presented the best tension $\mathrm{x}$ deformation commitment, with a tension of 6.2 $\mathrm{MPa}$, the 2nd best, and the greatest deformation, around 50 MPa. Lumina-Coat and Surgidry Dental F materials showed lower tension of rupture ( 0.4 and $0.1 \mathrm{MPa}$, respectively), and a deformation of $20 \mathrm{MPa}$. By analyzing the stress/strain graph, important information can be obtained regarding the elasticity, plasticity, stiffness, rupture, and energy that tissue can absorb before its rupture. The linear region of the curve corresponds to the elastic phase, where the deformation

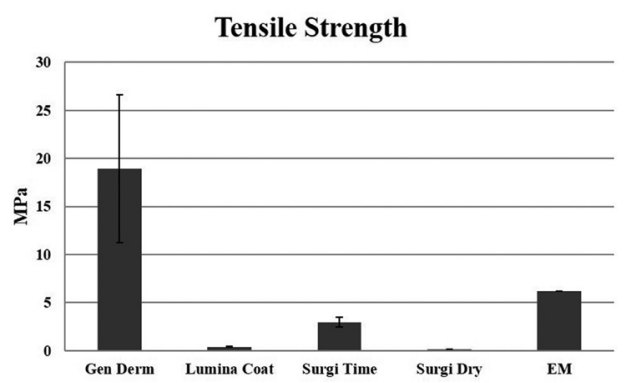

Fig. 4 Comparative results of tensions supported before rupture.

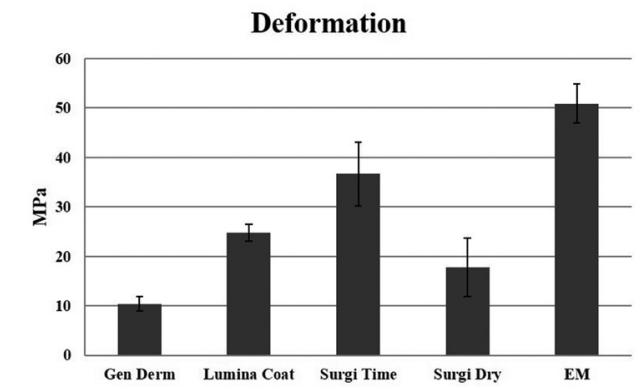

Fig. 5 Comparative results of strain deformation of each sample before rupture. 
increases linearly with the force applied, and the material will deform only while the load is being applied to it, returning to its original size when the load is removed. ${ }^{33}$ The nonlinear region corresponds to the plastic phase of the membranes in which the tissue becomes permanently deformed and it is not able to recover its initial length after the external force stopped. ${ }^{35,36}$ In the elastic region, the Experimental Membrane developed here presented the higher deformation and that presented higher tensile strength at the limit of the elasticity. In the plastic region, the Experimental Membrane presented the second highest tensile strength means, with mechanical characteristics with the highest average stress/ strain when compared to the other membranes tested.

The tissue biocompatibility of the Experimental Membrane was also evaluated in male Wistar rats, which received subcutaneous implants in evaluation times up to 84 days (data not shown). At the final evaluation time, areas with chronicle inflammation, light to mild fibroplasia, and also mild to moderate fibrosis were observed in both sides of the Experimental Membrane, similar to that of found in the control group (Lumina-Coat). These characteristics somehow complemented the results demonstrating that the experimental collagen-rich biomembrane developed here has a potential for application in guided bone regeneration.

\section{Conclusion}

Taken together, the results of the present study allow to conclude that the Experimental Membrane developed has physical-chemical and molecular characteristics similar to or better than that of the commercial products tested. The experimental collagen-rich biomembrane derived from porcine small intestinal submucosa demonstrated the potential for tissue-guided regeneration in dentistry with qualities for using as a physical barrier. It is also advantageous to be considered an extracellular matrix for being rich in macromolecules such as glycosaminoglycans, which actively participate in the process of bone neoformation in the niche in areas of cell growth, proliferation, and differentiation.

\section{Conflict of Interest}

None declared.

\section{Acknowledgments}

The authors are grateful to Universidade Anhanguera de São Paulo (UNIAN-SP) for the technical support. This study was developed as partial fulfillment of the requirements of Dr. Silva's PhD degree.

\section{References}

1 Andrée B, Bär A, Haverich A, Hilfiker A. Small intestinal submucosa segments as matrix for tissue engineering: review. Tissue Eng Part B Rev 2013;19(4):279-291

2 Khurshid Z, Husain S, Alotaibi H, et al. Chapter 18 - Novel Techniques of Scaffold Fabrication for Bioactive Glasses. In: Kaur G, ed. Biomedical, Therapeutic and Clinical Applications of Bioactive Glasses. Woodhead Publishing; 2019;497-519
3 O’Brien FJ. Biomaterials \& scaffolds for tissue engineering. Mater Today 2011;14:88-95

4 Park KM, Shin YM, Kim K, Shin H. Tissue engineering and regenerative medicine 2017: a year in review. Tissue Eng Part B Rev 2018;24(5):327-344

5 Zafar MS, Khurshid Z, Almas K. Oral tissue engineering progress and challenges. Tissue Eng Regen Med 2015;12:387-397

6 Stock UA, Vacanti JP. Tissue engineering: current state and prospects. Annu Rev Med 2001;52:443-451

7 Inanç B, Arslan YE, Seker S, Elçin AE, Elçin YM. Periodontal ligament cellular structures engineered with electrospun poly(DL-lactide-co-glycolide) nanofibrous membrane scaffolds. J Biomed Mater Res A 2009;90(1):186-195

8 Cho WJ, Kim JH, Oh SH, Nam HH, Kim JM, Lee JH. Hydrophilized polycaprolactone nanofiber mesh-embedded poly(glycolic-co-lactic acid) membrane for effective guided bone regeneration. J Biomed Mater Res A 2009;91(2):400-407

9 Park JK, Yeom J, Oh EJ, et al. Guided bone regeneration by poly(lactic-co-glycolic acid) grafted hyaluronic acid bi-layer films for periodontal barrier applications. Acta Biomater 2009;5(9):3394-3403

10 de Santana RB, de Mattos CM, Francischone CE, Van Dyke T. Superficial topography and porosity of an absorbable barrier membrane impacts soft tissue response in guided bone regeneration. J Periodontol 2010;81(6):926-933

11 Hutmacher DW. Scaffolds in tissue engineering bone and cartilage. Biomaterials 2000;21(24):2529-2543

12 Ahadian S, Khademhosseini A. Smart scaffolds in tissue regeneration. Regen Biomater 2018;5(3):125-128

13 Sheikh Z, Najeeb S, Khurshid Z, Verma V, Rashid H, Glogauer M. Biodegradable materials for bone repair and tissue engineering applications. Materials (Basel) 2015;8(9):5744-5794

14 Badylak SF, Tullius R, Kokini K, et al. The use of xenogeneic small intestinal submucosa as a biomaterial for Achilles tendon repair in a dog model. J Biomed Mater Res 1995;29(8):977-985

15 Hodde JP, Badylak SF, Brightman AO, Voytik-Harbin SL. Glycosaminoglycan content of small intestinal submucosa: a bioscaffold for tissue replacement. Tissue Eng 1996;2(3):209-217

16 Gilbert TW, Sacks MS, Grashow JS, Woo SL, Badylak SF, Chancellor MB. Fiber kinematics of small intestinal submucosa under biaxial and uniaxial stretch. J Biomech Eng 2006;128(6):890-898

17 Brown B, Lindberg K, Reing J, Stolz DB, Badylak SF. The basement membrane component of biologic scaffolds derived from extracellular matrix. Tissue Eng 2006;12(3):519-526

18 Hodde J, Record R, Tullius R, Badylak S. Fibronectin peptides mediate HMEC adhesion to porcine-derived extracellular matrix. Biomaterials 2002;23(8):1841-1848

19 Badylak SF, Freytes DO, Gilbert TW. Extracellular matrix as a biological scaffold material: structure and function. Acta Biomater 2009;5(1):1-13

20 McDevitt CA, Wildey GM, Cutrone RM. Transforming growth factor-beta1 in a sterilized tissue derived from the pig small intestine submucosa. J Biomed Mater Res A 2003;67(2):637-640

21 Voytik-Harbin SL, Brightman AO, Kraine MR, Waisner B, Badylak SF. Identification of extractable growth factors from small intestinal submucosa. J Cell Biochem 1997;67(4):478-491

22 Hodde JP, Ernst DM, Hiles MC. An investigation of the longterm bioactivity of endogenous growth factor in OASIS Wound Matrix. J Wound Care 2005;14(1):23-25

23 Hodde JP, Record RD, Liang HA, Badylak SF. Vascular endothelial growth factor in porcine-derived extracellular matrix. Endothelium 2001;8(1):11-24 
24 Nader HB, Ferreira TM, Paiva JF, et al. Isolation and structural studies of heparan sulfates and chondroitin sulfates from three species of molluscs. J Biol Chem 1984;259(3):1431-1435

25 Dietrich CP, Dietrich SM. Electrophoretic behaviour of acidic mucopolysaccharides in diamine buffers. Anal Biochem 1976;70(2):645-647

26 Gottlow J. Guided tissue regeneration using bioresorbable and non-resorbable devices: initial healing and long-term results. J Periodontol 1993;64:1157-1165

27 Bunyaratavej P, Wang HL. Collagen membranes: a review. J Periodontol 2001;72(2):215-229

28 Zellin G, Gritli-Linde A, Linde A. Healing of mandibular defects with different biodegradable and non-biodegradable membranes: an experimental study in rats. Biomaterials 1995;16(8):601-609

29 Kasaj A, Reichert C, Götz H, Röhrig B, Smeets R, Willershausen B. In vitro evaluation of various bioabsorbable and nonresorbable barrier membranes for guided tissue regeneration. Head Face Med 2008;4:22

30 Takata T, Wang HL, Miyauchi M. Migration of osteoblastic cells on various guided bone regeneration membranes. Clin Oral Implants Res 2001;12(4):332-338
31 Scantlebury TV. 1982-1992: a decade of technology development for guided tissue regeneration. J Periodontol 1993;64:1129-1137

32 Morgado DL, Rodrigues BVM, Almeida EVR, Seoud OAE, Frollini E. Bio-based films from linter cellulose and its acetates: formation and properties. Materials (Basel) 2013;6(6):2410-2435

33 Ishigaki T, Kubo K. Effects of eccentric training with different training frequencies on blood circulation, collagen fiber orientation, and mechanical properties of human Achilles tendons in vivo. Eur. J Appl Physiol 2018;118(12):2617-2626

34 Boerckel JD, Uhrig BA, Willett NJ, Huebsch N, Guldberg RE. Mechanical regulation of vascular growth and tissue regeneration in vivo. Proc Natl Acad Sci U S A 2011;108(37):E674 -E680

35 Marras WS, Walter BA, Purmessur D, Mageswaran P, Wiet MG. The contribution of biomechanical-biological interactions of the spine to low back pain. Hum Factors 2016;58(7):965-975

36 Abebe W, Pashley DH, Rueggeberg FA. Vasorelaxant effect of resin-based, single-bottle dentin bonding systems. J Endod 2005;31(3):194-197 